\title{
In Vitro Life Cycle, Micromorphological Studies and Reproductive Biology of an Anti-diabetic Fern
}

\author{
M. Gayathiri", I. Ramya Roselin, S. Sujatha and S. Catharin Sara \\ PG and Research Department of Botany, Holy Cross College (Autonomous), \\ Tiruchirappalli- 620 002, Tamil Nadu, India \\ *Corresponding author
}

\section{A B S T R A C T}

\begin{tabular}{|l|}
\hline K e y w o r d s \\
Adiantum caudatum \\
Linn., In vitro \\
culture, Spore \\
culture protocol, \\
Micromorphology \\
studies, \\
Reproductive \\
potential
\end{tabular}

\section{Introduction}

India has a rich population of Pteridophytes and most of the species appear in the region of South Indian Mountains called the Western and Eastern Ghats. Out of 1,000 species of Pteridophytes occurring in India, 170 species have been found to be used as food, flavour, dye, medicine, bio-fertilizers, oil, fiber and biogas production. Pteridophytes are ancient vascular plants having immense medicinal value. The ethno medicine is the mother of all modern drugs and recently the importance of the traditional knowledge based medicines are being utilized throughout the World. ${ }^{1-4}$

The pteridophytic plant selected for present investigation is Adiantum caudatum $\mathrm{L}$. belongs to family Adiantaceace. Adiantum is a genus comprising 200 species distributed globally from temperate to tropical regions and has many medicinal properties. In folklore medicine, Adiantum caudatum Linn. is used as a remedy to cure cough, diabetes, jaundice, 
fever, skin disease, diarrhea, wounds, and as a natural antibiotic. Ayurveda also describes that it would be useful to treat prameha (diabetes), Atisara, pravahika, cough, skin disease and fever. This plant is phytochemically and pharmacologically very potent and hence it is also cited very often in various systems of medicine. Various authors have explored the qualitative and quantitative phytochemical analysis for this plant. The distribution of this fern, includes lower slopes of the hills in Punjab, Rajasthan, Bengal, Tamil Nadu and Maharashtra. They generally prefer Humus-rich, moist, well-drained sites, ranging from foundation land soils to vertical rock walls. ${ }^{5-8}$

The plant body is distinctive in appearance, with dark, often black stipes and rachis, and bright green, often delicately - cut leaf tissue. Stipes 2-4 inches long tufted, spreading, fronds 6-12 inches long simply pinnate and rooting at the extremity. Pinnae $1 / 2-3 / 4$ inch long, nearly sessile, the lower line straight and horizontal, the upper rounded, more or less cut, the point usually blunt, the lower ones slightly stalked, texture coriaceous, the veins prominent the rachis and both surfaces of the frond villose, sori roundish or transversely oblong on the edge of the lobes. ${ }^{9}$

Application of in vitro spore germination for large-scale multiplication of certain species of ferns from the Western Ghats has been demonstrated. $^{10}$ Tissue culture of ferns through spores will ensure maximum genetic diversity within short period. More number of plants could be produced and the sustainability of the resources could be ensured. Moreover the invitro culture of spore and gametophytes overcome the pest and contamination experienced in conventionally soil based cultivation.

Adiantum genus is a large size of family and little is known about the prothallial structure and gametophyticphase. There is no report on spore culture and complete life cycle of this medicinal fern. The study of reproductive biology and micro propagation protocol leads to conservation of this fern. The procurement of secondary metabolites from tissue cultured plants will enhance and facilitate the study about medicinal utilization of this plant in future, especially antidiabetic properties. Hence the objectives of the present work are to explore in vitro life cycle of $A$. caudatum $\mathrm{L}$. and to drive a protocol for micro propagation of this fern and also to study its reproductive potential.

\section{Materials and Methods}

\section{Collection of experimental plants and spores}

Adiantum caudatum L. sporophyte plants (Fig.1a) were collected from the Kolli hills, Namakkal District, Eastern Ghats region of Tamil Nadu, during the month of January 2016. Voucher specimens (MG 001) were deposited in the Herbarium of Holy Cross College (Autonomous), Tiruchirappalli after proper authentication from Dr. S. John Britto S J, The Rapinat Herbarium and Centre for Molecular Systematics, St. Joseph's College (Campus), Tiruchirappalli-620 002.

The spores were collected by keeping the sporangia facing in a clean white sheet paper and waiting till dehiscence. Dark brown dust like spores were shed on the white sheet paper and these spores were collected and stored under $25^{\circ} \mathrm{C}$ on refrigerator.

\section{Medium preparation, spore inoculation and incubation}

Stock solution of Kc (Knudson's C 1946) ${ }^{11}$ and Kn (Knop's 1865) ${ }^{12}$ medium were prepared. The liquid medium was prepared from the stock solution and adjusted for $\mathrm{pH}$ 
5.8 to 6.0 . It was directly transferred to the glassware's like conical flask and Petri plate without adding agar. No carbon source was added in liquid medium. All the glass wares with medium were sterilized in the autoclave for 15 minutes at $15 \mathrm{lbs}$ pressure.

The spores were surface sterilized by using $0.1 \%$ sodium lauryl sulphate, washed in distilled water and dried. The dried spores were sprinkled on the surface of the two liquid medium prepared. The inoculated culture vessels were kept undisturbed and immobilized under $12 \mathrm{~h}$ photoperiod and 1800 lux light intensity and incubated at $25 \pm 2^{\circ} \mathrm{C}$. The cultures were observed for spore germination after 10-15 days.

Spore germination, growth area determination and micromorphological studies

The spore germination, prothalli formation and gametophytic development were observed continuously after 15 to 20 days after germination, by observing a prescribed focused microscopical area. Germination percentage was calculated by counting the spores germinated within the microscopical area and number of total spores. The growth area was calculated by measuring the length and breadth of the gametophytes in triplicate and mentioned in micrometers. Micromorphological characters of the gametophyte like apical notch, dermal hairs, marginal cells and number of sex organs were observed during 60-90 days period. A standardized measurement was carried out by adjusting the ocular meter and stage micrometer in a Weswox optik model TRHL 66 Stereomicroscope. After adjusting, the ocular meter, the stage micrometer was removed and gametophytes to be measured are viewed and the size of the gametophytes and its micromorphological characters were calibrated. The sex organs in the gametophytes was also counted and tabulated.

Thinning, subculturing and gender analysis

During presexual stage (40-50 days), the density of the population of the gametophytes was observed (200-250 gametophytes) and they were reduced (75-100) by transferring them to petriplates (by thinning) and subcultured. Number of sex organs was observed during 60-90 days period. The sex organs in the gametophytes were also counted in triplicates for calculating reproductive potential on two medium. Intergametophytic selfing and Intragametophytic selfing forms the basis for the study of Reproductive biology ${ }^{13}$. The syngamy is determined by the formation and development of embryo. Sporophytes were determined to have been produced sexually by examination with a compound microscope after fertilization.

Gender was scrutinized by counting male, female and bisexual prothalli separately in each vessels subcultured for the two medium studied. The reproductive potential of any species is mainly calculated by tracing the bisexual and selfing potential of that species. Genetic load is measured by counting the percentage of bisexual gametophytes failing to produce sporophytes. Thus reproductive potential of these ferns can be ascertained by the steps presented below,

Bisexual Potential $=$

(Bisexual Gametophytes)(Total Gametophytes) $\times 100$

Selfing Potential $=\frac{\text { Sporophytes }}{\text { Bisexual Gametophytes }} \times 100$

Genetic Load $=$

$\frac{\text { Non Sporophyte Producing Gametophytes }}{\text { Bisexual Gametophytes }} \times 100$

All the ontogeny, developmental stages and images related to reproductive structures were 
micro photographed using Weswox optik model TRHL - 66 stereomicroscope fitted with Pentax camera.

\section{Results and Discussion}

Germination and development of $A$. caudatum L. spores in Kc medium

The trilete rugulose spores $(20 \times 50 \mu \mathrm{m})$ (Fig.1b) germinated on 12 days after spore sowing. Germ filament emerged with rhizoids and the germination is of Vittaria type. Germ filament elongate and form 7-8 cells stage (Fig.1d) and grows up to 15-17 celled stage. During 25 days time this one dimensional filament undergo two dimensional change with anticlinal and periclinal division by the meristematic cell at the apical notch formed on the filament. The prothallial plate develops into a cordate shaped gametophyte with dermal hairs and evidenced Adiantum type of development.

The microscopic observation of germination reveals that A.caudatum Linn. spores has started germinating at 12 days time and gametophyte development proceeded in cultures of Kc medium (Fig.1c). Vittaria type of germination and Adiantum type of prothallial development fall in line with classification of Nayar and Kaur ${ }^{14}$. The spores having little stored food materials, seldom germinate in the wild whereas spores can germinate under in vitro conditions easily by supplementing with hormones and additives. Thus in vitro culture techniques have been used to study different aspects of spore germination, growth and development of gametophytes and sporophytes in ferns ${ }^{15}$.

After 45 days of the growth, a well developed presexual prothalli is formed with broad wings. The micromorphology of the gametophytes evidenced, undulated margins without marginal hairs and perfect $U$ shaped apical notch with pluricellular meristem. Few rhizoids are present at the ventral surface. The length between anterior apical notch area and posterior rhizoidal area is very short without any cushion like structures (Fig.2a).

Sex organs initiated after $60-80$ days. The number of archegonia is very few (Fig. 2b) when compared to the antheridia (Fig. 2d) in Knudson's medium. These gametophytes are hermaphrodite and hence possess antheridia and archegonia (Fig. 2c) on the same thalli. The first leaf is formed after fertilization in the hermaphrodite gametophytes and root was also produced consequently (Fig. 2e). Sporophyte formation was seen after 120 days and the percentage of sporophyte formation is 69 on Kundson's medium (Fig. 3a and b, Table 2). Thus Knudson's medium is considered to be the optimal medium for the developmental protocol of this fern A.caudatum L. (Fig. 4). According to our observation apart from hermaphrodite prothalli there are antheridiate, and archegoniate (10-15) prothalli separately formed on $\mathrm{Kc}$ medium. The proportion of antheridiate prothalli was high when compared to the archegoniate prothalli. Very few gametophytes produced first leaf in the gametophytes possessing archegonia.

In the present study, A.caudatum L. showed clone forming nature, so that the antheridiate prothallus posses considerable power of regeneration. Numerous younger gametophytes sprouted from the margins of the old living male (mother) prothalli after 200 -260 days and are called as miniature gametophytes (Fig. 3e). The regenerating power of the old prothalli in culture shows the autotrophic and rejuvenating potential of this species. (Fig. 3b).Various authors have quoted this nature of cloning forming tendency. Atkinson ${ }^{17}$ and Sara and Manickam ${ }^{18}$ has also reported such proliferative growth on Thelypteris erubescens andThelypteris 
confluens.

Gametophytes of several epiphytic species of Polypodiaceae have been shown to be perennial and clone-forming. In P. pellucidum, besides being cordate in young and early mature stages, the older gametophytes became ruffled, lobed, and branched and lived for over two years although some of the older parts died. ${ }^{19}$ This clone-forming habit may function to increase the gametophytes' living space and to prolong the life span. ${ }^{14}$ Our experimental plant also belong to the order Polypodiaceae and possess the same character of clone forming like the Polypodium (Fig. 3e) species studied earlier. These extended clonal and perennial gametophytes continuously form gametangia on their new proliferations, and thus enhance the possibility of interaction with other gametophytes established previously or later in the natural vicinity.

\section{Experimental studies of A.caudatum L.}

\section{Germination and growth area}

The spores in Kn (Knops) medium germinated on 12 days after spore sowing. Germ filament emerged with rhizoids and the germination is Vittaria type. The maximum germination of $95 \%$ occurred on knudson's medium and $80 \%$ germination occured on knop's medium (Table 1). Knudson's medium and knop's medium were not supplemented with any carbon sources or hormones.

The prothalli grown on $\mathrm{Kn}$ medium on 25 days time undergo two dimensional change with anticlinal and periclinal division by the meristematic cell at the apex of the filament. The prothallial plate develops into a cordate shaped gametophyteand evidenced Adiantum type of development (Fig. 3c).

The growth area calculated for the prothalli on 30, 60 and 90 days for Kc an Kn medium were shown in Table 1. The growth area for Kc medium was $17.9 \mathrm{~mm}$, whereas it is $7.2 \mathrm{~mm}$ in $\mathrm{Kn}$ medium on 30 days old gametophyte. The vegetative growth was gradual in Kc medium, So that in 60 days it increased up to $24.9 \mathrm{~mm}$ and $10.1 \mathrm{~mm}$ in $\mathrm{Kc} \& \mathrm{Kn}$ medium respectively. The micromorphological changes takes place during this period. The same prothallial growth attained $47.7 \mathrm{~mm}$ and 14.7 $\mathrm{mm}$ at 90 days time in the cultures of $\mathrm{Kc}$ and $\mathrm{Kn}$ medium. Hence an increased growth area was evidenced in $\mathrm{Kc}$ medium rather than $\mathrm{Kn}$ medium (Table 1 and Fig. 5).

The results of growth pattern of gametophyte in kundson's medium and knop's medium shows the effect of medium on vegetative and reproductive development of the experimental plant. The optimum medium $(\mathrm{Kc})$ was found to contain more Ammonium and Iron than $\mathrm{Kn}$ medium. Hence both vegetative and reproductive growth is facilitated by $\mathrm{Kc}$ medium even though the substratum differ as liquid rather than solid (under culture conditions), because naturally the plant is a lithophyte and clinked to the crevices of rocks and multiply through spore dispersal in nature. The natural niche is modified and liquid medium facilitates the growth and reproduction of this plant. Hence the protocol (Fig. 4) is useful in Ex situ conservation of this important anti-diabetic fern. ${ }^{16}$

\section{Micromorphology and sex organ}

Micromorphological changes including, apical notch, dermal hair, pluricellular meristem and perfect cordate shape play a vital role in sex organ formation. Micromorphologyin Kc medium shows cordate shaped gametophyte with ' $U$ ' shaped apical notch and hairs with sex organs where as spathulate gametophytes without proper apical notch, hairs and sex organs could be seen in kn medium. The gametophytes grown in Kc medium produced sex organs and underwent fertilization leading to the formation of sporophyte. 
Table.1 Germination and Growth area of 30, 60 and 90 days old gametophytes of A. caudatum L in two different medium

\begin{tabular}{|c|c|c|c|c|c|c|}
\hline \multirow[t]{2}{*}{ S.No. } & \multirow[t]{2}{*}{ Medium } & $\begin{array}{c}\text { Days of } \\
\text { development }\end{array}$ & $\%$ Germination & $\begin{array}{l}\text { Length } \\
\text { (in } \mu \mathrm{m})\end{array}$ & $\begin{array}{l}\text { Breadth } \\
\text { (in } \mu \mathrm{m} \text { ) }\end{array}$ & $\begin{array}{l}\text { Growth area } \\
\text { (in mm) }\end{array}$ \\
\hline & & 12 & 95 & - & - & - \\
\hline \multirow{3}{*}{1.} & \multirow{3}{*}{$\mathrm{KC}$} & 30 & -- & $349.6 \pm 3.20$ & $614.4 \pm 5.84$ & $17.9 \pm 19.088$ \\
\hline & & 60 & -- & $392.8 \pm 4.32$ & $754.8 \pm 2.48$ & $24.9 \pm 12.197$ \\
\hline & & 90 & & $485.2 \pm 1.23$ & $984.0 \pm 7.36$ & $47.7 \pm 10.667$ \\
\hline \multirow{4}{*}{2.} & \multirow{4}{*}{$\mathrm{KN}$} & 12 & 80 & - & - & - \\
\hline & & 30 & - & $230.2 \pm 2.88$ & $316.0 \pm 6.44$ & $7.2 \pm 9.803$ \\
\hline & & 60 & - & $256.6 \pm 3.34$ & $394.2 \pm 6.53$ & $10.1 \pm 9.622$ \\
\hline & & 90 & - & $281.2 \pm 1.32$ & $523.6 \pm 1.14$ & $14.7 \pm 9.985$ \\
\hline
\end{tabular}

Fig.4 Protocol for spore culture of Adiantum caudatum L.

Rugulose trilete spores collected from palode (kerala) cultured on liquid Kc medium at pH 5.8

10-12 days time

Proximal rhizoid cell and uniseriate germs cell formed (Vittaria type of germination)

15-25 days time

8-10 celled stage gametophyte or prothalli become wider plates of cordate gametophyte

25-40 days time

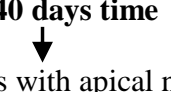

Gametophyte with marginal glandular hairs with apical notch (Adiantum type of development)

50-90 days time

Ontogeny of sex

Antheridiate (60-75 d)

No. of Antheridia (9-10)

Release of sperms

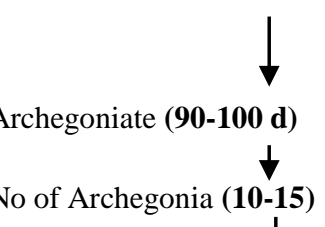

Archegoniate (90-100 d)

No of Archegonia (10-15)
Hermophrodite (90-100d)

Antheridia/Archegonia

(2-3) (22-25)

Release of sperms Egg formation $\quad$ Release of sperm / Egg

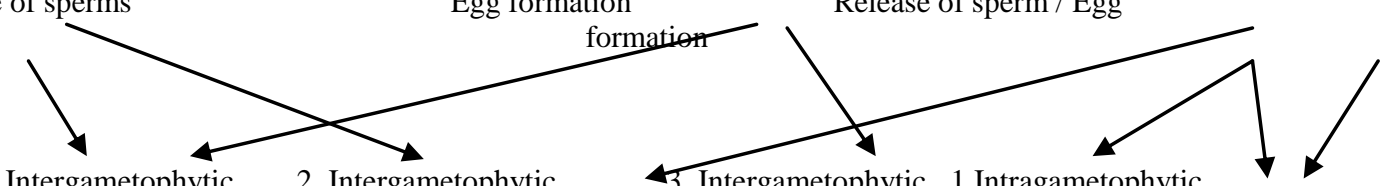

1.Intergametophytic 2. Intergametophytic

3. Intergametophytic 1.Intragametophytic
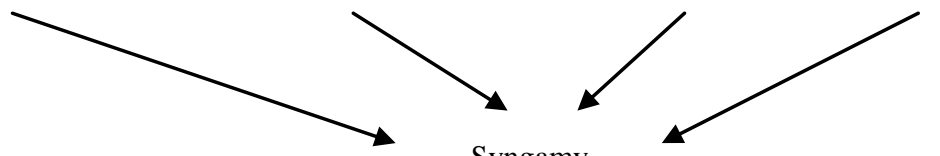

Embryo formation

Sporophyte with first leaf having glandular hairs was obtained

Acclimatization 
Table.2 Micromorphology of gametophytes of A.caudatum Linn grown on knudson's and knop's medium on $80^{\text {th }}$ day

\begin{tabular}{|c|c|c|c|c|c|c|c|}
\hline Medium & Germination type & Developmental type & Rhizoids & Gametophyte Shape & Apical notch & Hairs/ margins & Sex organs \\
\hline $\begin{array}{l}\text { Kundson's } \\
\text { medium }\end{array}$ & Vittaria type & Adiantum type & Present & Cordate & U Shaped & No haris & Present \\
\hline Knop's medium & Vittaria type & Adiantum type & Few & Spathulate & U shaped & No hairs & No sex organs \\
\hline
\end{tabular}

Table.3 Gender and Reproductive potential of Adiantum caudatum L. in Knudson's C and Knop's medium after 150 days of culture

\begin{tabular}{|c|c|c|c|c|c|c|c|c|c|c|}
\hline \multicolumn{6}{|c|}{ Gender } & \multicolumn{5}{|c|}{ Reproductive potential analysis } \\
\hline Medium & q & $\hat{0}$ & $q \hat{0}$ & V.G & T.G & SP & N.S.P.G & B.P\% & S.P \% & G.L\% \\
\hline Kc medium & 5.0 & 5.0 & 90 & 00.00 & 100 & 69.00 & 30 & 90 & 76.66 & 33 \\
\hline Kn medium & 9.0 & 21.0 & 00.00 & 70.00 & 100 & 9.00 & 2.00 & 00 & 9.00 & 00 \\
\hline
\end{tabular}

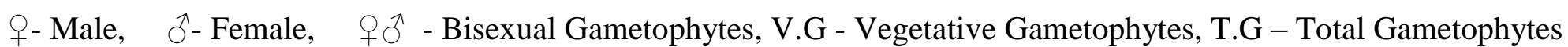
SP - Sporophyte Produced, N.S.P.G - Non-Sporophyte Producing Gametophytes, B.P - Bisexual Potential, S.P - Selfing potential G.L - Genetic Load 
Figure.1 Habitat, Habit, Spores and culture of A.caudatum Linn on Kc medium
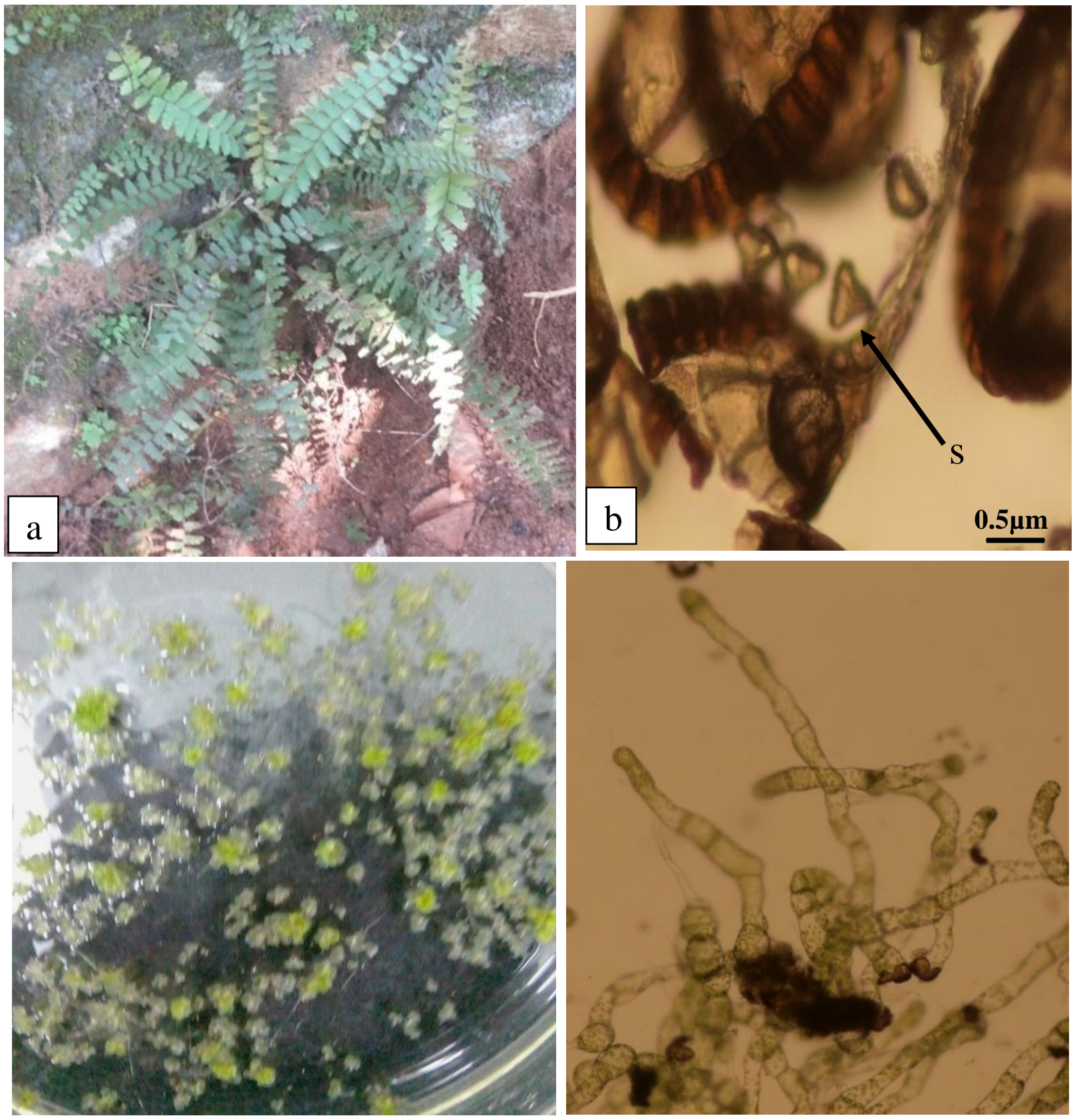

1a- Habitat and Habit of A. caudatum L. a lithophytic plant

1b- Spores of A. caudatum L. $(1 \mathrm{~cm}=0.5 \mu \mathrm{m})$

1c- Liquid grown gametophytes on petriplates

1d- 25 days old 8 celled prothalli of A.caudatum L. $(1 \mathrm{~cm}=5 \mu \mathrm{m})$ 
Figure.2 Gametophytic and Sporophytic growth stages of A.caudatumLinn on Kc medium

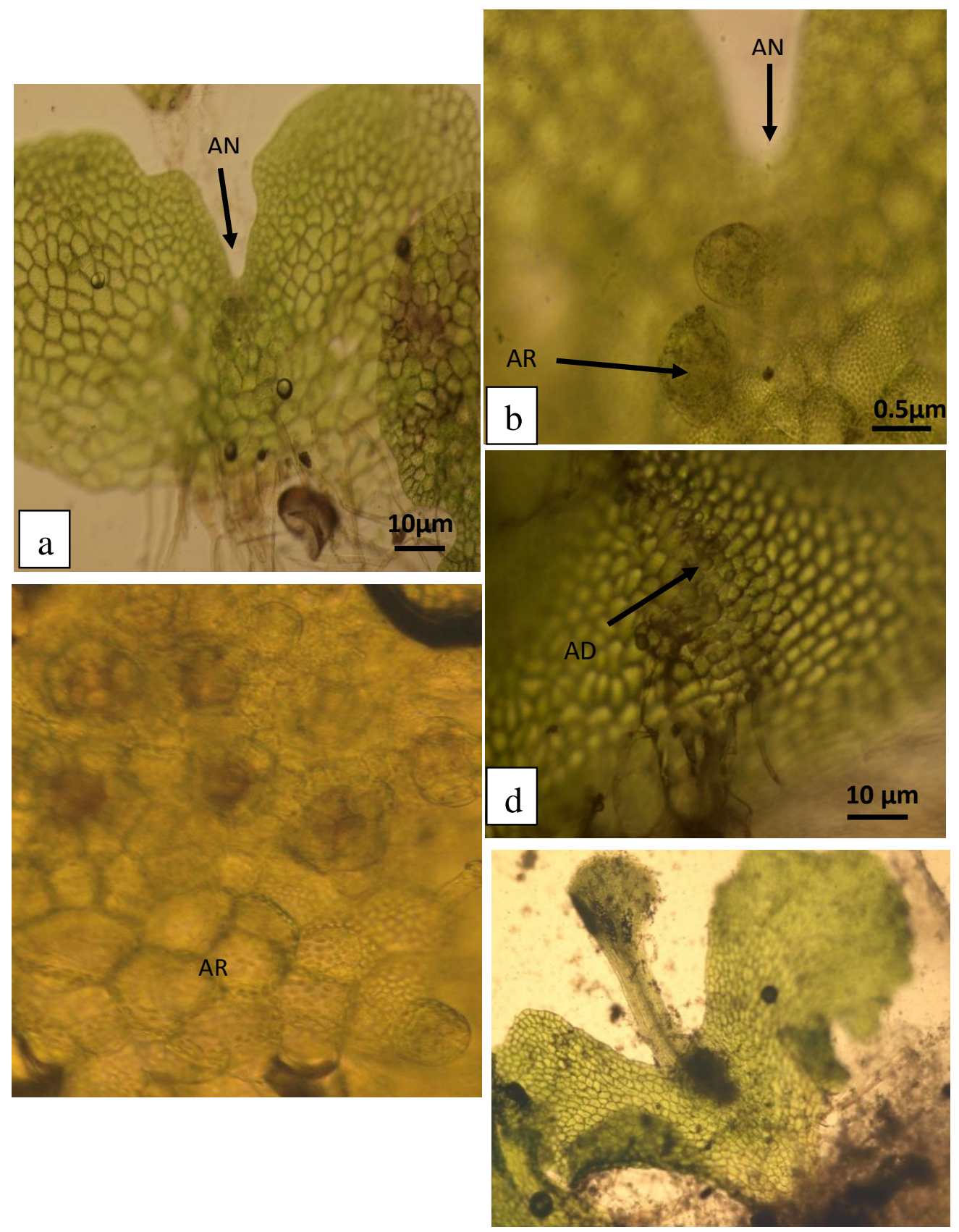

2a - 45 days old gametophyte morphology with apical notch and broad wings. $(1 \mathrm{~cm}=10 \mu \mathrm{m})$ (AN- Apical Notch) $2 \mathrm{~b}$ - Shows the formation of archegonia near the apical notch $(1 \mathrm{~cm}=0.5 \mu \mathrm{m})$ (AR- Archegonia)

2c- Hermaphrotite prothalli with antheridia and archegonia on the same prothallus $(1 \mathrm{~cm}=0.5 \mu \mathrm{m})(\mathrm{AR}, \mathrm{AD}-\mathrm{Archegonia}$, Antheridia)

$2 \mathrm{~d}$ - Antheridial distribution on the gametophyte near the rhizoids and away from the notch $(1 \mathrm{~cm}=10 \mu \mathrm{m})$ $2 \mathrm{e}$ - Baby sporeling emerging from gametophyte 
Figure.3 Sporophytes of A. caudatum Linn on Kc medium and gametophytic stages on Kn medium

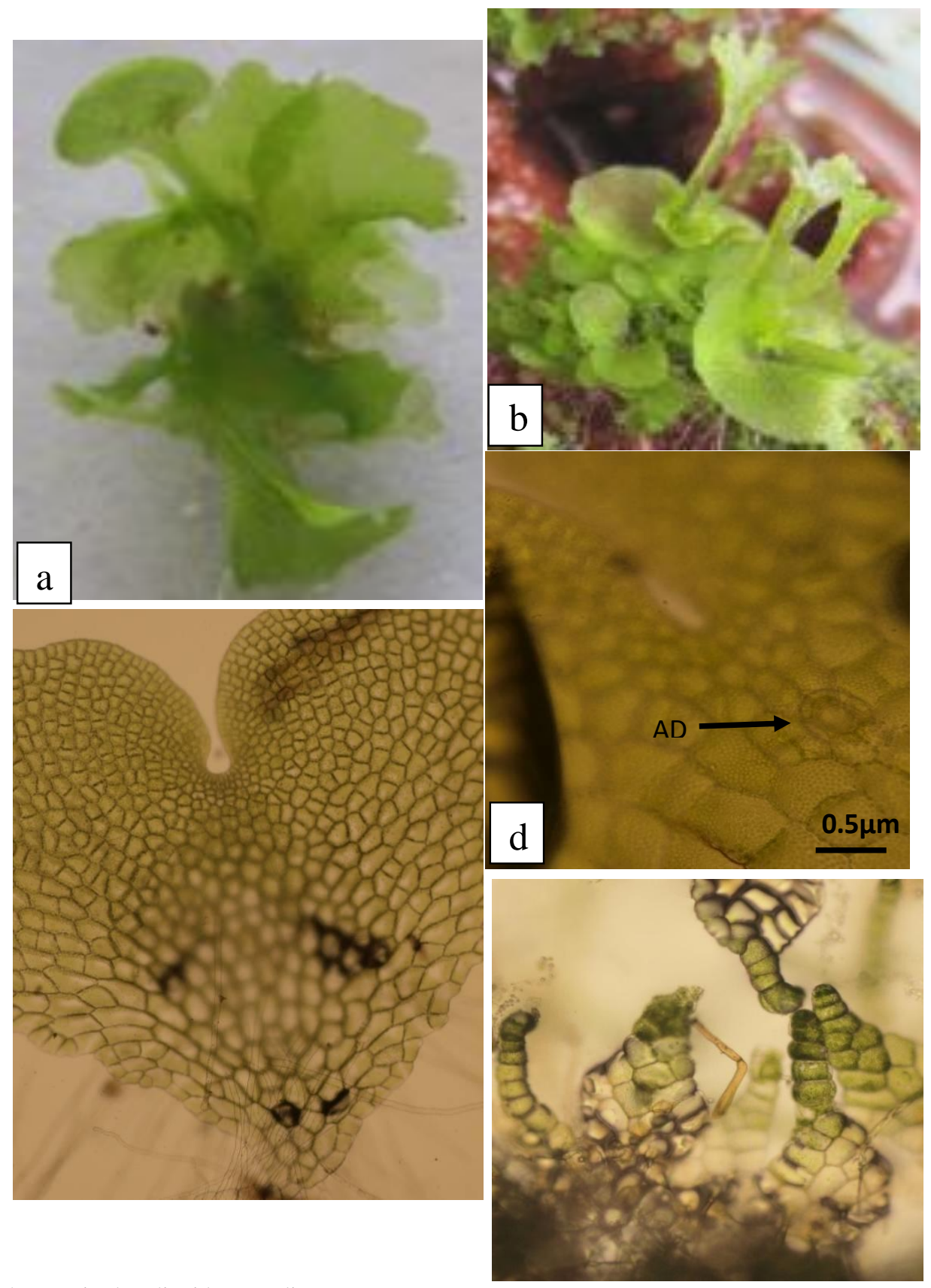

$3 \mathrm{a}$ and $3 \mathrm{~b}$ - Sporophytes raised on liquid $\mathrm{Kc}$ medium

3c - Showing 80 days old gametophyte of A.caudatum L. in Kn medium $(1 \mathrm{~cm}=10 \mu \mathrm{m})$

$3 \mathrm{~d}$ - Showing 90 days old gametophyte with archegonia in $\mathrm{Kn}$ medium $(1 \mathrm{~cm}=0.5 \mu \mathrm{m})$

$3 \mathrm{e}-150$ days old gametophyte showing the formation of miniature gametophyte $(1 \mathrm{~cm}=10 \mu \mathrm{m})$ 
Figure.5 Gametophytic growth area of Adiantum caudatum L. in two different medium on 30, 60 and 90 days

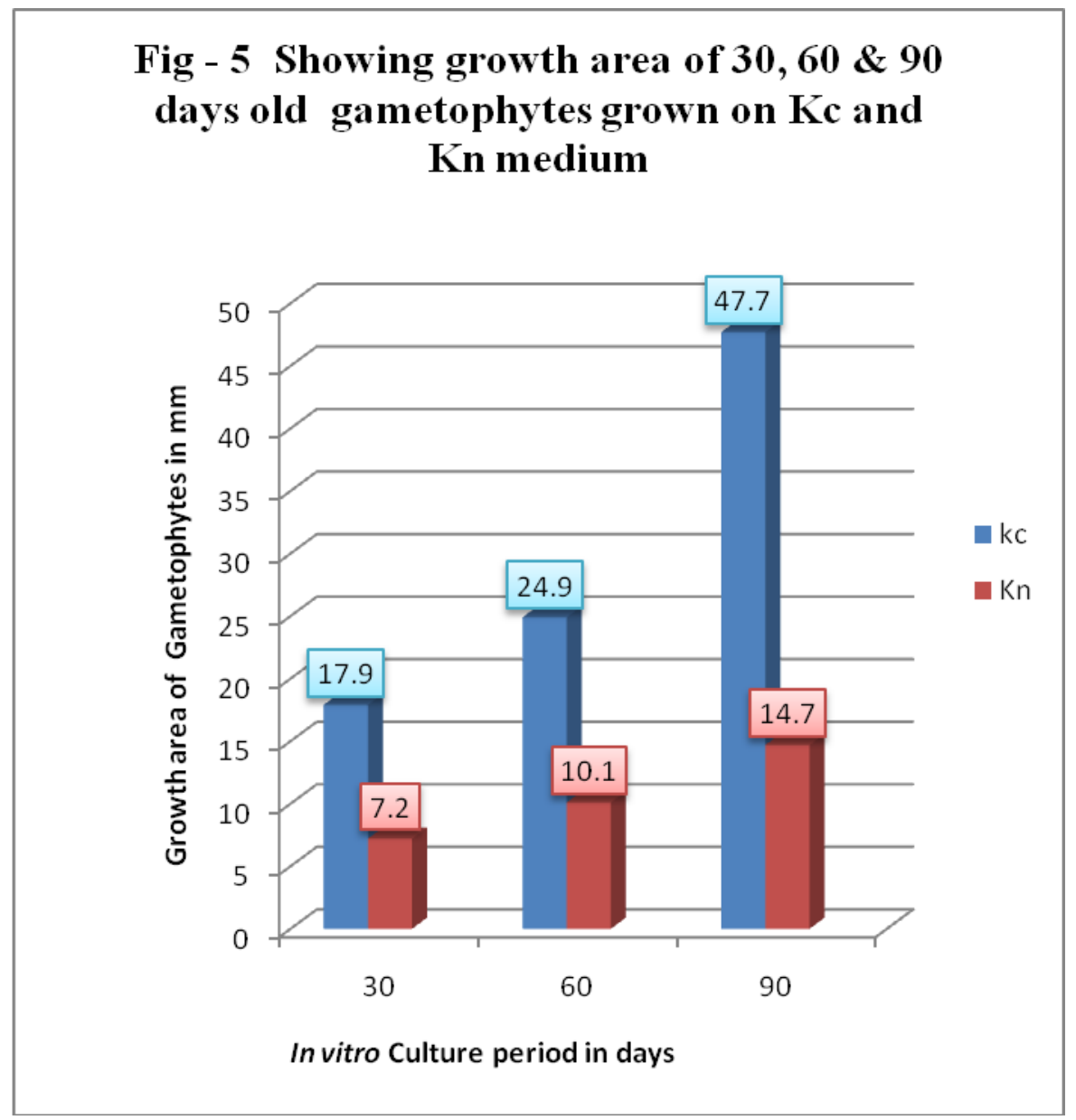

In $\mathrm{Kn}$ medium there is no such sex organs formed even after 80 days time (Table 2). There is no hermaphrodite gametophytes but archegoniate (Fig. 3d), antheridiate and more vegetative gametophyte (Fig. 3c) were seen in $\mathrm{kn}$ medium leading to clone formation (Fig. 3e) which in turn favour intergametophytic selfing later.

The results indicate the monoecious and dioecious nature of gametophytes under two medium and culture conditions, which is a sophisticated in vitro environment. Dioecious nature was seen in $\mathrm{Kc}$ medium at $\mathrm{pH}$ 5.8. From a single kind of spore, three types of gametophytes resulted in our study. Distribution of sex organs in the gametophytes also vary in two medium studied. This shows that external environment i.e. medium, its quantity, $\mathrm{pH}$ and light plays an important role in determining sex. The same concept was put forth by Ghosh et al., ${ }^{20}$, and according to him in Environmental Sex Determination (ESD), gender is decided after conception, depending on the environment, rather than being genetically fixed. In their study, Culcita macrocarpa gametophytes were cultured under varying nutrient conditions. 
Initially, most of the gametophytes of Culcita macrocarpa were male and subsequently hermaphrodite under different nutrition. The result indicates that its sex determination is protandry. All nutrient conditions were favourable for developing male prothalli but only good environment (high nutrient) was favourable for female gametophyte growth. In all respects, female gametophytes were much larger, than the other types of gametophytes. Hermaphroditic gametophytes were larger than male gametophytes, which were larger than asexual gametophytes. This idea was supported by many other authors. ${ }^{21} \& 22$

\section{Gender and reproductive potential of A.caudatum L.}

The ability and frequency of intragametophytic and intergametophytic selfing determines the reproductive potential of homosporous pteridophytic species. Protocol (Fig. 4) clearly explains the possibility of syngamy and embryo formation of this experimental plant, A.caudatum L. Regarding Gender in A.caudatum L. the male, female, hermophrodite and vegetative gametophyte observed and counted from 100 gametophytes from the microscopic field was tabulated on $\mathrm{Kc}$ and $\mathrm{Kn}$ medium (Table 3). The reproductive potential analysis was done by calculating bisexual potential and selfing potential, which in turn was calculated based on the sporophytes formed and number of bisexual gametophytes present in the culture. The genetic load was ascertained by calculating the non-sporophyte producing gametophyte and bisexual gametophyte.

Accordingly out of 100 gametophytes studied, 90 bisexual gametophytes produced in $\mathrm{Kc}$ medium resulted in 69 sporophytes (Table 3). The selfing potential calculated is $76.66 \%$, and the genetic load calculated for $\mathrm{Kc}$ medium is $33 \%$. The same observation shows absence of bisexual gametophtyes, but resulting in 9 sporophytes in $\mathrm{Kn}$ medium. The selfing potential calculated is $9 \%$ and genetic load is $0 \%$. The bisexual potential for $\mathrm{Kc}$ medium studied is $90 \%$ and $0 \%$ for $\mathrm{Kn}$ medium (Table 3). High bisexual potential and low genetic load equipped the species for long distance dispersal in natural population. Our monocultures are uniform in their metabolism and in every growth stage, optimum conditions required were provided so that the selfing potential, Bisexual potential and genetic load is scrutinized perfectly. Most of the information known about the reproductive biology of ferns is from research on terrestrial ferns which encounter very different environmental events from epiphytic ferns.The trait of clone forming as mentioned in the section of spore culture in Kc medium which was found in our cultures supports intergametophytic mating, because sporophytes are formed even in $\mathrm{Kn}$ medium (9 in number as in table 3) with large number of vegetative prothalli This observation finds a relation between intergametophytic mating and clone formation in this plant.

By studying gametophyte ontogeny and testing for the presence of genetic load it is possible to analyze species of homosporous ferns and determine their basic mating system operative in nature. Genetic load is also an obstacle to successful intragametophytic selfing, and the degree of genetic load has been used to measure the sporophyte heterozygosity and probable breeding system. ${ }^{23}$ Hence the controlling factors of the mating system in ferns may be complex, with different aspects contributing more or less depending upon the species and / or the environmental conditions. ${ }^{24}$

Successful reproduction of ferns depends on early germination, development to maturity, attainment of bisexual status and absence of genetic load. In vitro monocultures of $A$. caudatum on $\mathrm{Kc}$ showed higher bisexual potential 90 (Table 3). Calculated genetic load is low in Kc medium (33) in a single 
analysed concentration and $\mathrm{pH}$ of the medium and it also due to low unisexual gametophytes (5 antheridiate and 5 archegoniate). The same result is recorded in Thelypteris confluens. ${ }^{18}$ Hence the gametophytes of experimental plant proliferates under in vitro condition, Whereas $\mathrm{Kn}$ medium indicates that high frequency of vegetative prothalli leads to less chance for inter as well as intragametophytic selfing and less chance of dispersibility.

Concludingly the important results of the present work on this plant were summarized as follows. Germination was effective on knudson's medium with Vittaria type of germination and Adiantum type of gametophyte development. The illustrations and interpretations through tables, figures, graphs and especially protocol derived in the present experimental plant shows that Knudsons medium as optimal medium. Micro morphologically gametophytes possess pluricellular meristems, apical notch, unicellular glandular hairs on 80 days. Reproductive potential was high in $\mathrm{Kc}$ medium. Fertilization is effective after 120 days time. This protocol could be referred for further spore culture techniques and conservation of this plant. The clone forming nature of lithophytic ferns was discussed in detailed and related to polypodiaceous ferns.

\section{Acknowledgements}

The Authors would like to acknowledge Dr.Sr.A.Christina Bridge, the present Principal and Dr.Sr.Jesuin Francis, the former Principal, Holy Cross College (Autonomous), Tiruchirappalli and Dr.P.Francisca, Head of the Department of Botany for the support and facilities provided to carry out this work.

\section{References}

1. Singh, L., 2001. Ethnobotanical uses of some Pteridophytic species in Maipur.
Indian Fern Journal. 18(1): 14-17.

2. Easa, P.S., 2003. Biodiversity documentation for Kerala Part 5, Pteridophytes. Kerala Forest Research Institute Peechi Kerala. KRFRI. Hand book No. 17: 20-27.

3. Manickam, V.S., and Irudayaraj, V.1992. Pteridophytic Flora of the Western Ghats-South India. BI Publications Ltd., New Delhi, Pp. 652.

4. Johnson, M., Manickam, V.S., Benniamin., A. and Irudayaraj, V. 2008. Conservation of endangered ferns of Western Ghats through Micropropagation: 183-191.

5. Brahmachari, G., Mondal, S., Chatterjee, D., and Brahmachari, A.K,. 2003. Phytochemicals and biological activities of Adiantum species. Journal Sciences. Ind. Res 62: 1119-1130.

6. Dildar Ahmed Muhammad Mehbook Khan and Ramsha Saeed., 2015. Comparative Analysis of Phenolics, Flavonoids, and Antioxidant and Antibactrial Potential of Methanolic, Hexanic and Aqueous extracts from Adiantum caudatum L. Leaves, Article of Autonio Segura Carretro. 4(2): 394 - 409.

7. Ibraheim, Z.Z., Ahmed, A.S., and Gouda, Y.G., 2011. Phytochemical and biological studies of Adiantum capillusveneris L. Saudi Pharm. J. 19: 65 -74.

8. Pan, C., Chen, Y.G., Ma, X.Y., Jiang, J.H., He, F., and Zhang, Y., 2011. Phytochemical constituents and pharmacological activities of plants from the genus Adiantum- A review. Tropical Journal of Pharmacy. Res, 10: 681- 692.

9. Colonel, R.H., and Beddome, F.L.S,. 1969. Hand book of the ferns of British India. Pp. 83-84.

10. Sara, S.C., Manickam, V.S., and Antonisamy, R., 1998. Regeneration in kinetin -treated gametophytes of Nephrolepis multiflora (Roxb.) Jarret in 
Morton. Current Science 75: 503-508.

11. Knops, N., 1865. Quantitative Untersuchungan uber die Ernahrungsprozesse der pflangen Land wirtsch Vers, stn. 7: 93- 107.

12. Knudson, L., 1946. A nutrient solution for the germination of orchid seed. Bulletin of AmericanOrchid Society15: 214217.

13. Peck, J.H., Peck, C.J., and Farrar, D.R., 1990. Influences of life history attribution on formation of local and distant fern population, American fern journal, Vol 80: 126-142.

14. Nayar, B.K., and Kaur, S., 1964. Types of prothallial development in homosporous fern, Phytomorphology, Vol-20: 179188.

15. Nayar, B.K., and Kaur, S., 1971. Gametophytes of homosporous ferns. Bot. Rev. 37: 295-396.

16. Johnson Marimuthu, 1., and Visuvasam Soosai Manickam., 2011. Ex situ conservation of two threatened ferns of the

Western

Ghats through in vitro spore culture, Journal of Threatened Taxa, 3(7): 1919 1928

17. Atkinson, L. R., 1971. The Gametophyte Of Thelypteris Erubescens. American Fern Journal 61: 183-186.

18. Sara, C.S., and Manickam, V.S., 2007. In vitro developmental ontogeny and life cycle of a rare fern species - Thelpteris confluens (Thunp) Morton. Indian Journal of Biotechnology. 2007,Vol 6:
372-380.

19. Dassler, C.L., 1995. Significance of gametophyte form in tropical, epiphytic ferns. Ph.D. dissertation. Iowa State University, Ames.

20. Esha Yadav., Munesh Mani., Phool Chandra., Neetu Sachan., and A. K. Ghosh, A.K., 2012. A review on therapeutic potential of Lygodium flexuosum Linn. Pharmacogn Rev. 6(12): 107-114.

21. Jean - Michel Guillon., and Daniel Fievet., 2003. Environmental Sex deremination in response to light and biased sex ratios in Equisetum gametophytes. Journal of Ecology banner, Vol, 91(1): 49-57.

22. Yao- Moan Huang., Hsueh-Mei Chou., and Wen- liang Chiou., 2004. Density affects gametophytes growth and sexual Expression of Osmunda cinnamomea (Osmundaceae: Pteridophyta). Annals of Botany. (www.aob.oupjournals.org), 94: 229-232

23. Cousens, M.I., 1988. Reproductive strategies of pteridophytes, in Plant Reproductive Ecology: Patterns and Strategies, edited by J. lovett doust and L. lovett doust. Oxford University Press, New York: 307-328.

24. Soltis, D.E., and Soltis, P.S., 1987. Polyploidy and breeding systems in homosporous pteridophyta: A re evaluation. Amer. Natur. In press. 413415.

\section{How to cite this article:}

Gayathiri, M., I. Ramya Roselin, S. Sujatha and Catharin Sara, S. 2018. In Vitro Life Cycle, Micromorphological Studies and Reproductive Biology of an Anti-diabetic Fern. Int.J.Curr.Microbiol.App.Sci. 7(07): 3590-3603. doi: https://doi.org/10.20546/ijcmas.2018.707.418 